\title{
Improved method for simultaneous determination of the carbon isotopic composition and concentration of atmospheric $\mathrm{CO}_{2}$ using CF-IRMS
}

\author{
EUN-JI YU, KWANG-SIK LEE
}

Korea Basic Science Institute, Chungbuk 28119, Republic of Korea

Determination of the concentration and isotopic composition of atmospheric $\mathrm{CO}_{2}$ is essential for the identification of sources and sinks of anthropogenic $\mathrm{CO}_{2}$ and the monitoring of various emission reduction techniques, such as geological $\mathrm{CO}_{2}$ storage. A customized and convenient method was proposed to determine the carbon isotopic composition and concentration of $\mathrm{CO}_{2}$ of air samples simultaneously using a continuous flow-isotope ratio mass spectrometer (CF-IRMS) interfaced with a GasBench II (Thermo Fisher Scientific, Bremen, Germany). Convenient sampling and isotopic analysis were achieved using $12-\mathrm{mL}$ Exetainer vials with open tops, screw caps, and rubber septa for both air sampling and isotopic analysis. The proposed method differs from previously reported methods in several aspects, including the convenience of sampling and analysis, and high accuracy and precision despite small sample consumption. Combined with the Keeling plot technique, this method allows accurate determination of the isotope composition of atmospheric $\mathrm{CO}_{2}$. The proposed technique can be applied in various studies involving the isotopic composition and concentration of $\mathrm{CO}_{2}$, such as diagnosing of cancer in oncology, tracing of anthropogenic $\mathrm{CO}_{2}$ and monitoring of leakage from subsurface $\mathrm{CO}_{2}$ storage. 